\title{
Physicochemical, Thermal, Rheological and Morphological Characteristics of Starch from Three Indian Lotus Root (Nelumbo Nucifera Gaertn) Cultivars
}

\section{Anna Syed and Sukhcharn Singh*}

Department of Food Engineering and Technology, Sant Longowal Institute of Engineering and Technology, Longowal, Punjab, India

\begin{abstract}
The starches separated from three different Indian lotus root cultivars were investigated for physicochemical, thermal, pasting and morphological properties. Amylose content and water binding capacity of starches ranged between 18.75 to $20.84 \%$ and $91.8 \%$ to $102.3 \%$ respectively. The transition temperatures ( $T$ o, $T p$ and $T c$ ) and enthalpy of gelatinization $(\Delta \mathrm{Hgel})$ were determined using differential scanning calorimetry. DSC spectrum of lotus starch showed that the peak temperature was from $71.74^{\circ} \mathrm{C}$ to $75.317^{\circ} \mathrm{C}$. Pasting properties of starches were measured using the Rapid Visco Analyser (RVA). Pasting temperature and peak viscosity were between $(60.3$ to $72.7^{\circ} \mathrm{C}$ ) and $(7827.6$ to $10123.3 \mathrm{cp})$ respectively. Turbidity values of gelatinized starch pastes increased during refrigerated storage. Scanning electron micrographs showed that the granules of lotus root starch varied from round to elliptic with a size range of $10.2-50.7 \mu \mathrm{m}$.
\end{abstract}

Keywords: Lotus root starch; Physico-chemical Properties; RVA; SEM; Differential scanning calorimetry

\section{Introduction}

Lotus root (Nelumbo nucifera Gaertn.) is the fat root of a plant from an aquatic emergent angiosperm that belongs to the Nelumboleaceae family and the genus Nelumbo Adans. In India its common names are Nadru (Kashmiri), Bihi and Kamal Kakdi. They are actually modified tubers storing energy in the form of starch. The exterior of this root is covered with a peel that is white or reddish brown in color. The roots are smooth, grey-white in color and measure about $10-20 \mathrm{~cm}$ in length and $6-10 \mathrm{~cm}$ in diameter. Internally, the root has white, crunchy flesh with mild sweet, water chestnut like flavor. The cut sections reveal visually appealing display of symmetrically arranged air canals (holes) traversing along the length of the root. Lotus is an important economic aquatic crop. Every part of the plant has economic value. In India lotus is used in many ways like pickle preparation and cooking. The lotus root can be processed into flour and used in preparation of number of products. Together with the lotus seeds, the edible root contains an abundant amount of starch, sugars, proteins, lipids, vitamins and minerals. They are easily digested and are a good and nutritious food for all ages.

Composition of the lotus reveals starch as the main component. The fresh root contains $15 \%$ of starch. Starch as a raw material has various applications in the manufacturing of food products like imparting texture and consistency and to acts as functional ingredients like thickeners, stabilizers and gelling agent. Growing demand for starches in the food industry has created interest in newer sources of this polysaccharide. Wang and White [1] suggested the most important properties to consider when determining the uses of starch in food systems and other industrial applications are physicochemical (e.g., gelatinization and retrogradation) and functional (e.g., solubility, swelling, water absorption, syneresis and rheological behavior of pastes and gels) properties Due to tremendous importance of starch and starch based products, food scientists are trying to obtain starches from non-conventional sources as already well Properties lotus root starch documented by Moorthy [2]. Zhong Geng et al. [3] reported that lotus starches possess good clarity and gel strength. Starches from botanical sources have diverse physicochemical and functional properties and are affected by environmental conditions greatly. A detailed knowledge of the characteristics of these starches would facilitate their utilization in industries; enable tailoring of the properties by physical and or chemical modification to specific applications and bringing economic benefit to the local people in the long run. Therefore the present study has been carried out to explore the various physicochemical, thermal, morphological and rheological properties of the lotus root starch.

\section{Materials and Methods}

\section{Materials}

Fresh Lotus roots (grown in Jammu \& Kashmir (KLR), Punjab (PLR), Haryana (HLR)) were procured locally from the market of respective state. They were washed in running water to remove surface dirt, dipped in $0.5 \%$ sodium hypochlorite for 15 min [4] to surfacesterilize, rinsed in water, air-dried to remove surface moisture, and stored at $12^{\circ} \mathrm{C}$ to $14^{\circ} \mathrm{C}$ for further processing. At this temperature roots can stored for 12-15 days.

\section{Isolation of starch}

Isolation of starch from the lotus roots was carried out by the method described for sweetpotato by Singh et al. [5] with little modification in process and proportion of chemical used (Figure 1). The roots were washed, peeled and then shredded. The shreds were then dipped in a solution containing $0.12 \%$ potassium metabisulphite (KMS) and about $0.25 \%$ citric acid for about 1 hour to improve the

*Corresponding author: Sukhcharn Singh, Department of Food Engineering and Technology, Sant Longowal Institute of Engineering and Technology, Longowal, Punjab, India, E-mail: sukhcharns@yahoo.com

Received April 01, 2013; Accepted May 03, 2013; Published May 10, 2013

Citation: Syed A, Singh S (2013) Physicochemical, Thermal, Rheological and Morphological Characteristics of Starch from Three Indian Lotus Root (Nelumbo Nucifera Gaertn) Cultivars. J Food Process Technol S1: 003. doi:10.4172/21577110.S1-003

Copyright: (c) 2013 Syed A, et al. This is an open-access article distributed under the terms of the Creative Commons Attribution License, which permits unrestricted use, distribution, and reproduction in any medium, provided the original author and source are credited. 


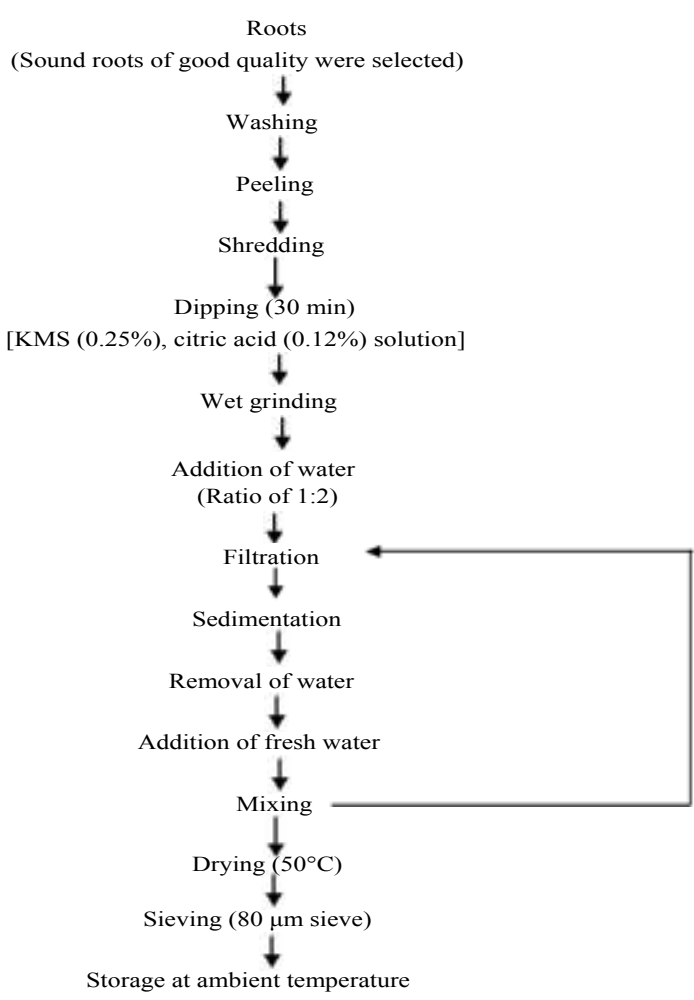

Figure 1: Flow chart for the isolation of lotus root starch.

color of starch. These shreds were then homogenized into a paste in a blender by adding water to facilitate the crushing. The homogenate was then filtered through a 100 mesh sieve and the filtrate was kept undisturbed for 5-6 hours. The crude starch thus obtained was treated with $0.2 \%$ aqueous $\mathrm{NaOH}$ for $1-2 \mathrm{~h}$. followed by several washings with cold water to remove traces of alkali until the supernatant no longer showed any pink color with phenolphthalein. The precipitated starch cake thus obtained was dried overnight in an oven at $400^{\circ} \mathrm{C}$. The starch was ground to pass it through a 100 mesh sieve $(149 \mathrm{~mm})$, packed in double plastic bags and stored in refrigeration conditions for 20-30day for further analysis.

\section{Physicochemical properties lotus root of starch}

Moisture content: The moisture content of the starch samples was determined in triplicate by oven-drying of representative samples of about 2 to $3 \mathrm{~g}$ and heated for $24 \mathrm{hrs}$ at $105^{\circ} \mathrm{C}$ to constant weight.

Protein ash: The protein content of isolated starch and root was determined in duplicate by the Micro Kjeldahl method $(\mathrm{N} \times 6.25)$, as described in the AACC-approved method [6] and ash content was determined by heating at $550^{\circ} \mathrm{C}$ for $4 \mathrm{hrs}$ (AOAC methods) [7].

Starch: The starch content of raw roots was determined by acid hydrolysis using the method suggested by Rahman et al. [8]. The reducing sugar obtained on hydrolysis was measured by Lane and Eynon's methods describe by Ranganna [9]. The total reducing sugar multiplied by a factor of 0.9 to give the starch content of lotus roots.

Amylose content: Apparent amylose contents of the starch samples were determined by the method of Williams et al. [10]. The absorbance was measured at $625 \mathrm{~nm}$ (UV Spectrophotometer, Electronics Corp. of India Limited, Hyderabad, India).
Size and shape of starch granules: The starch granules size and shape were determined microscopically by a light microscope fitted with a calibrated eyepiece (HELMET HUND, GMBH, Wilhelm-will str.7, Wetzlar, Germany) using 50\% glycerol-distilled water solution at ambient temperature to prevent sample drying during light microscopy, with a magnification factor of $400 \times$ as described by Elizabeth et al. [11] and Jyothi et al. [12].

Water binding capacity (WBC): WBC of lotus stem starches was determined by the method described by Yamazaki [13] as modified by Medcalf and Gilles [14]. A suspension of 5 grams of starch (dry weight basis) in $75 \mathrm{ml}$ distilled water was agitated for 1 hour and then centrifuged at $3000 \mathrm{rpm}$ for 10-15 minutes. The free water was then removed from the wet starch which was then drained for $10 \mathrm{~min}$ and wet starch was then weighed

$$
\text { Water binding capacity }(\%)=\frac{\text { Weight of residual starch }}{\text { Weight of sample }} \times 100
$$

Oil binding capacity (OBC): Oil binding capacity of the lotus stem starches was determined using the method described by Yamazaki [13] A suspension of $5 \mathrm{~g}$ starch (dry weight basis) in $75 \mathrm{ml}$ oil was agitated for $1 \mathrm{~h}$ and centrifuged $3000 \mathrm{rpm}$ for $10 \mathrm{~min}$. The free oil was removed from the wet starch, which was then drained for $10 \mathrm{~min}$. The residue was then weighed

$$
\text { Oil binding capacity }(\%)=\frac{\text { Weight of residual starch }}{\text { Weight of sample }} \times 100
$$

Swelling power and solubility index: The swelling power and solubility index were determined by the method of Leach et al. [15]. The values for swelling power were reported in grams per gram and that of solubility index in percent.

Paste clarity: The clarity (\% transmittance at $650 \mathrm{~nm}$ ) was measured by using the method of Singh et al. [16]. A 1\% aqueous suspension of starch at neutral $\mathrm{pH}$ was heated in a boiling water bath with intermediate shaking. After that the suspension was cooled for 1 hour at $25^{\circ} \mathrm{C}$. The transmittance at $650 \mathrm{~nm}$ was read against the water blank.

Sediment volume: Sediment volume was determined as described by Singh et al. [16]. One gram of starch on dry basis was weighed into beaker and $95 \mathrm{ml}$ of distilled water was then added. The $\mathrm{pH}$ of the starch slurry was adjusted to 7.0 using $5 \% \mathrm{NaOH}$ or $5 \% \mathrm{HCl}$, following which the slurry was cooked in a boiling water bath for $15 \mathrm{~min}$. Distilled water was then added to bring the total weight to $100 \mathrm{~g}$. The mixture was then stirred thoroughly and transferred to a $100 \mathrm{ml}$ graduated cylinder. The cylinder was sealed with aluminum foil and the starch slurry was kept at room temperature for $24 \mathrm{~h}$. The volume of the sediment, consisting of starch granules, was then measured.

\section{Color determination}

The color of the starches was measured by a colorimeter (Model I-5 Green Macbeth) as L, a, and b values. The $L$ value states the position on the white/black axis, a value states the position on the red/green axis, and $b$ values state the position on the yellow/blue axis. The color difference has been calculated as

$$
\Delta E=\sqrt{(\Delta L)^{2}+(\Delta a)^{2}+(\Delta b)^{2}}
$$

\section{Turbidity}

The turbidity of suspensions of the starch samples was measured as described by Perera and Hoover [17]. An aqueous starch suspension (1\%) was heated in a boiling water bath for $1 \mathrm{~h}$ with constant stirring 
and then cooled for $1 \mathrm{~h}$ at $30^{\circ} \mathrm{C}$. The samples were stored for 5 days at $4^{\circ} \mathrm{C}$ in a refrigerator under covered conditions to prevent loss/gain of moisture and turbidity was determined every $24 \mathrm{~h}$ by measuring absorbance at $640 \mathrm{~nm}$ (UV Spectrophotometer, Electronics Corp. of India Limited, Hyderabad, India) against water blank.

\section{Pasting properties}

The pasting properties of the starches were evaluated with the Rapid Visco Analyser (RAV-4, Newport Scientific, Warriewood, Australia). Viscosity profiles of different starches were recorded using starch suspensions $(6 \%, \mathrm{w} / \mathrm{w} ; 28 \mathrm{~g}$ total weight). A programmed heating and cooling cycle was used, where the samples were held at $50^{\circ} \mathrm{C}$ for $1 \mathrm{~min}$, heated to $95^{\circ} \mathrm{C}$ at $12^{\circ} \mathrm{C} / \mathrm{min}$, held at $95^{\circ} \mathrm{C}$ for $2.5 \mathrm{~min}$, before cooling from 95 to $50^{\circ} \mathrm{C}$ at $12^{\circ} \mathrm{C} / \mathrm{min}$ and holding at $50^{\circ} \mathrm{C}$ for 2 min. Parameters recorded were pasting temperature, peak viscosity, trough viscosity (minimum viscosity at $95^{\circ} \mathrm{C}$ ), final viscosity (viscosity at $50^{\circ} \mathrm{C}$ ), breakdown viscosity (peak-trough viscosity) and setback viscosity (final-trough viscosity).

\section{Thermal properties}

The gelatinization characteristics of lotus root starches were determined using a differential scanning calorimeter (DSC-7, Perkin-Elmer, Norwalk, CT). Starch (3.5 mg, dry basis) was loaded into aluminum pan and distilled water was added with the help of a Hamilton microsyringe to achieve a starch- water suspension containing $70 \%$ water. Samples were hermetically sealed and allowed to equilibrate for $1 \mathrm{~h}$ at room temperature before analysis. The DSC analyzer was calibrated using indium and an empty aluminium pan was used as reference. Sample pans were heated at a rate of $10^{\circ} \mathrm{C} / \mathrm{min}$ from 20 to $100^{\circ} \mathrm{C}$. The temperature at the onset of gelatinization $(\mathrm{To})$, the temperature at the peak $(T \mathrm{p})$, the temperature at conclusion the $(T c)$ and the enthalpy $(\Delta H)$ were determined.

\section{Morphological studies}

Scanning electron micrographs (SEMs) were taken with a Jeol JSM7500 scanning electron microscope (Jeol Ltd., Tokyo, Japan). Starch samples were suspended in ethanol to obtain a $1 \%$ suspension. One drop of the starch ethanol suspension was applied on an aluminum stub using double-sided adhesive tape and the starch was coated with gold-palladium (60:40). An accelerating potential of $20 \mathrm{kV}$ was used during micrography.

\section{Statistical analysis}

The data reported in all the tables were subjected to one way analysis of variance (ANOVA) using Minitab Statistical Software version 13 (Minitab, Inc., State College, USA).

\section{Results and Discussion}

The process for the isolation of starch from lotus root was standardized. Starch slurry readily turned brown during the preprocesses, which included peeling, shredding, and grinding. This may be due to the high level of polyphenol oxidase enzymes [18]. The shredded roots were treated with KMS and citric acid to improve the color of starch. Further alkali treatment with $0.2 \% \mathrm{NaOH}$ was also given in order to remove the proteins that are associated with the starch granules. Starch obtained was approximately $99.4 \%$ pure starch.

\section{Physiochemical properties of lotus root starch}

The chemical analysis of lotus root starch from all the three sources is shown in (Table 1). The ash content of these starches was found to be almost same in the range of $(0.2 \%$ to $0.4 \%)$ shows that starch contains negligible proportion of inorganic matter. The lotus root starches also exhibited low levels of proteins $(0.12 \%$ to $0.16 \%)$. Low protein content may be attributed to the fact that the water soluble proteins are washed out during the isolation. The amylose content of all the three varieties was determined to reveal the internal quality of the starch and its functionality. PLR starch was found to contain highest percentage of amylose $(21.16 \pm 0.29 \%)$ than HLR $(20.84 \pm 0.03 \%)$ and KLR $(18.75$ $\pm 0.04 \%)$. These values is found close to the value $19.5 \%$ and $23.9 \%$ reported by Anil and Corke [19] for root crop and Man J [20] for lotus seed starch. The size of starch granules varied from $10 \mu \mathrm{m}-50 \mu \mathrm{m}$. The water binding capacities of starch from PLR exhibited highest water binding capacity of $(102.3 \pm 0.2 \%)$, followed by starch from KLR (100.2 $\pm 0.2 \%)$ and HLR $(91.8 \pm 0.2 \%)$. Hoover and Sosulki [21] observed that the formation of hydrogen and covalent bonds by the hydroxyl groups between the starch chains lowers water binding capacity. The differences in water binding capacity are mainly due to differences in average amylopectin branch chain-length among the starches. The difference in the degree of availability of water binding sites among the starches may also have contributed to the variation in water binding capacity among different starches [22]. The affinity of starch towards oil was found to be less than that for the water. The starch from KLR which showed a high oil binding capacity of $(114.5 \pm 0.3 \%)$ than PLR starch $(51.6 \pm 0.3 \%)$ and HLR starch $(38.63 \pm 0.15 \%)$. Retention of water and oil in swollen starch granules highly influence the eating quality of the food [23]. Sediment volume is the ratio of the sediment gel to the dry weight of starch. The sediment volume of the KLR starch was the highest $(86.6 \pm 1.5 \mathrm{ml})$ followed by PLR and HLR starch with

\begin{tabular}{|c|c|c|c|}
\hline Composition analysis (\%by weight) & KLR & PLR & HLR \\
\hline Moisture & $9 \pm 0.2$ & $9 \pm 0.05$ & $9 \pm 0.02$ \\
\hline Ash & $0.2 \pm 0.02$ & $0.4 \pm 0.02$ & $0.4 \pm 0.01$ \\
\hline Protein & $0.12 \pm 0.01$ & $0.16 \pm 0.01$ & $0.14 \pm 0.01$ \\
\hline Amylose & $18.75 \pm 0.04$ & $21.16 \pm 0.29$ & $20.84 \pm 0.03$ \\
\hline Size $(\mu \mathrm{m})$ range & $10.2-50.7$ & $10.2-50.7$ & $10.2-50.7$ \\
\hline Shape & Round, oval round, elongated & Round, elliptic, elongated & Round, oval round and elongated \\
\hline Water binding capacity $\%$ & $100.2 \pm 0.2$ & $102.3 \pm 0.2$ & $91.8 \pm 0.2$ \\
\hline Oil binding capacity $\%$ & $114.5 \pm 0.3$ & $51.6 \pm 0.3$ & $38.63 \pm 0.15$ \\
\hline Sediment volume & $86.6 \pm 1.5$ & $50.3 \pm 2.5$ & $47 \pm 2$ \\
\hline Swelling power $(\mathbf{g} / \mathbf{g})$ & $12.57 \pm 0.02$ & $2.1 \pm 0.01$ & $2.12 \pm 0.02$ \\
\hline Solubility $\%$ & $1.65 \pm 0.03$ & $3.33 \pm 0.02$ & $3.31 \pm 0.03$ \\
\hline Paste clarity & $14.06 \pm 0.11$ & $9.2 \pm 0.2$ & $8.6 \pm 0.2$ \\
\hline
\end{tabular}

Values are the means \pm standard deviations of the means at least three determinations $n=3$.

Table 1: Physicochemical characteristics of KLR, PLR and HLR starch. 
Citation: Syed A, Singh S (2013) Physicochemical, Thermal, Rheological and Morphological Characteristics of Starch from Three Indian Lotus Root (Nelumbo Nucifera Gaertn) Cultivars. J Food Process Technol S1: 003. doi:10.4172/2157-7110.S1-003

Page 4 of 7

the values of $(50.3 \pm 2.5 \mathrm{ml})$ and $(47 \pm 2 \mathrm{ml})$ respectively. The highest value for KLR starch could be attributed to the large size of its oval and elongated starch granules. The extent of interaction between starch chains, within the amorphous and crystalline domains of the starch granule can be assessed with the help of swelling power and solubility such as amylose/amylopectin ratio, the structural characteristics of amylose and amylopectin, phosphate and lipid contents and granular morphology. Swelling power and solubility can be used to assess the extent of interaction between the starch chain, within the amorphous and crystalline domains of starch granules. The swelling power was found to be highest in starch from the KLR $(12.57 \pm 0.02 \%)$, whereas no significant differences in swelling power was observed in the other two starches $(2.1 \pm 0.01 \%)$ for PLR and $(2.12 \pm 0.02 \%)$ for HLR. The solubility value of KLR was 1.65 which was much lower the value of PLR (3.33) and HLR (3.31). Amylopectin is considered to contribute to water absorption and swelling and pasting of starch granules, whereas amylose tends to retard these processes [24]. The linear amylose diffuses out of the swollen granules and makes up the continuous phase outside the granules as a restraint to swelling. So, an inverse correlation is found between amylose content and swelling power [25]. Therefore this case is validated because among these three starches PLR and HLR starches have higher amylose content and therefore less swelling power as compared KLR starch. Lee et al. [26] reported that the swelling power of starch has been depend upon the water holding capacity of starch molecules by hydrogen bonding. Hydrogen bonds stabilizing the structure of the double helices in crystallites are broken during gelatinization and are replaced by the hydrogen bonds with water, and swelling is regulated by the crystallinity of the starch [27]. Starch from the KLR showed the highest transmittance of $(14.06 \pm 0.01 \%)$ thus was clearer than PLR and HLR starches that showed transmittance of $(9.2 \pm 0.2) \%$ and $(8.6 \pm 0.2) \%$ respectively. The decrease in the \% transmittance upon heating was due to restricted swelling of starches.

\section{Color}

The color values of lotus root starches are shown in (Table 2). The ' $L$ '-value was found to be highest in KLR starch $(85.636 \pm 0.001)$ followed by PLR starch $(83.374 \pm 0.001)$ with the lowest value shown by HLR starch $(81.577 \pm 0.002)$, thus it can be interfered that KLR starch is whiter than the other two starches. In case of 'a'-value, it was found to be lowest in KLR starch $(5.144 \pm 0.001)$ and highest in PLR starch with the value of $(6.782 \pm 0.002)$ with HLR starch having an intermediate value of $(6.558 \pm 0.001)$. Higher the ' $a$ '-value of starch higher is its redness. The yellowness was highest in PLR starch with the ' $b$ '-value of $(21.811 \pm 0.001)$ and lowest in KLR starch $(17.722 \pm 0.01)$ and PLR starch had the intermediate value of (10.296). The color of starch is due to the presence of polyphenolic compounds, ascorbic acid and carotene and has impact on its quality. Any pigmentation in the starch is carried over to the final product. This reduces the quality, hence acceptability of starch product [28].

\section{Turbidity}

Turbidity values for all the three samples increased progressively with the storage period of 5 days and then became constant (Figure 2). The increase in turbidity during storage has been attributed to the interaction between leached amylose and amylopectin chains that led to development of junction zones, which reflect or scatter a significant amount of light. Turbidity development in starch pastes during storage have been reported to be affected by factors such as granule swelling, granule remnants, leached amylose and amylopectin, amylose and amylopectin chain lengths [29].

\section{Pasting properties}

Pasting properties of all the three different starch varieties have been summarized in table 3. Pasting properties of starches influenced by size, rigidity and amylose to amylopectin ratio of starch granules. A significant difference was observed in the pasting properties of these starches. Pasting curves of lotus root starch showed pasting characteristics typical of tuber and root starches with high peak viscosity development and rapid shear thinning at high temperature. KLR starch exhibited the highest peak viscosity of $(10123.3 \pm 1.5 \mathrm{cp})$ followed by the viscosity of PLR $(8060.6 \pm 2.5 \mathrm{cp})$ and HLR $(7827.6$ $\pm 2.08 \mathrm{cp}$ ) (Figure 3 ). The increase in viscosity with temperature may be attributed to the removal of water from the exuded amylose by the granules as they swell [30]. Peak viscosity is indicative of water binding capacity and ease with which starch granules are disintegrated and it is often correlated with final product quality [31]. It can be affected by the molecular structure of amylopectin, starch water concentration, lipids, residual proteins and, granule size [32,33].

In case of trough viscosity HLR starch showed the highest value of $(2857 \pm 2 \mathrm{cp})$ followed by PLR starch $(2831 \pm 2 \mathrm{cp})$ and KLR starch $(2796 \pm 2 \mathrm{cp})$. It was observed that breakdown viscosity (BV) is highest

\begin{tabular}{|c|c|c|c|c|}
\hline Source & $\mathbf{L}$ & $\mathbf{a}$ & $\mathbf{B}$ & $\Delta \mathbf{E}$ \\
\hline KLR & $85.636 \pm 0.001$ & $5.144 \pm 0.001$ & $7.720 \pm 0.001$ & $21.811 \pm 0.001$ \\
\hline PLR & $83.374 \pm 0.001$ & $6.782 \pm 0.002$ & $10.694 \pm 0.002$ & $18.94 \pm 0.02$ \\
\hline HLR & $81.577 \pm 0.002$ & $6.558 \pm 0.001$ & $10.296 \pm 0.002$ & $17.22 \pm 0.01$ \\
\hline
\end{tabular}

Values are the means \pm standard deviations of the means at least three determinations $n=3 L=$ white/black axis, $a=$ red/green axis, $b=$ yellow/blue axis

Table 2: Color values of KLR, PLR and HLR starches.

\begin{tabular}{|c|c|c|c|}
\hline \multirow{2}{*}{$\begin{array}{c}\text { Pasting } \\
\text { properties }\end{array}$} & \multicolumn{3}{|c|}{ Source } \\
\cline { 2 - 4 } & KLR & PLR & HLR \\
\hline PV (cp) & $10123.3 \pm 1.5$ & $8060.6 \pm 2.5$ & $7827.6 \pm 2.08$ \\
\hline TV (cp) & $2796 \pm 2$ & $2831 \pm 2$ & $2857 \pm 2$ \\
\hline BV (cp) & $7326.6 \pm 1.5$ & $5230.3 \pm 2.5$ & $4969.6 \pm 2.5$ \\
\hline FV (cp) & $3427 \pm 2$ & $3830 \pm 2$ & $3753 \pm 3$ \\
\hline SBV (cp) & $631 \pm 2$ & $997.3 \pm 1.5$ & $894 \pm 2$ \\
\hline $\mathbf{P}$ Temp ( $\left.{ }^{\circ} \mathbf{C}\right)$ & $60.3 \pm 0.4$ & $72.7 \pm 0.04$ & $69.3 \pm 0.02$ \\
\hline
\end{tabular}

Values are the means \pm standard deviations of the means at least three determinations $\mathrm{n}=3, \mathrm{PV}=$ peak viscosity, $T V=$ Trough viscosity, $\mathrm{BV}=\mathrm{Breakdown}$ viscosity, $\mathrm{FV}=$ Final viscosity, $\mathrm{SBV}=\mathrm{Set}$ back viscosity, and $\mathrm{P}$ Temp= Pasting temperature.

Table 3: Pasting properties of KLR, PLR and HLR starches.

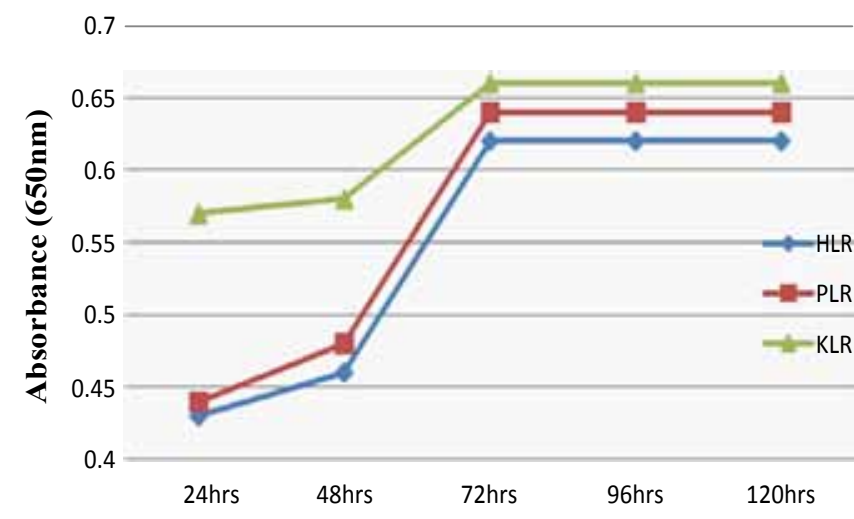

Figure 2: Effect of storage on the turbidity of KLR, PLR and HLR starch pastes. 


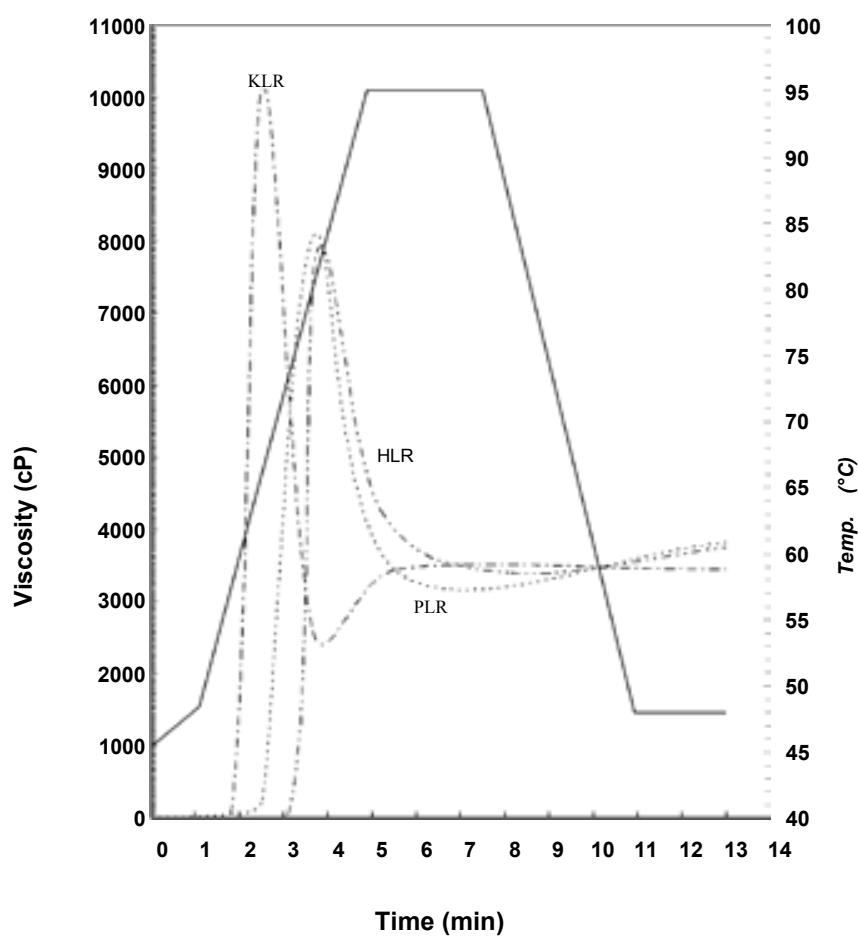

Figure 3: Pasting characteristics of KLR, PLR and HLR starches.

in KLR starch $(7326.6 \pm 2.5 \mathrm{cp})$ but lowest in that of HLR starch (4969 $\pm 2.5 \mathrm{cp})$, PLR starch found to have an intermediate value of (5230.3 \pm $2.5 \mathrm{cp})$. The breakdown is caused by the disintegration of gelatinized starch granule structure during continued stirring and heating [33]. Rani and Bhattacharya [34] reported that the differences among starch in breakdown viscosities are related to differences in rigidity of swollen granules. Final viscosity (FV) which is related to form a viscous paste was highest in PLR starch ( $3830 \pm 2 \mathrm{cp})$ followed by HLR starch (3753 $\pm 3 \mathrm{cp})$ and KLR starch $(3427 \pm 2 \mathrm{cp})$. The increase in final viscosity might be due to the aggregation of the amylose molecules [34]. The setback (final viscosity minus trough viscosity) is the viscosity increase resulting from the rearrangement of amylose molecules that have leached from swollen starch granules during cooling and is generally used as a measure of the gelling ability or retrogradation tendency of starch [35]. PLR starch was found to have the highest set back viscosity of $(999.3 \pm 1.5 \mathrm{cp})$ followed by HLR starch $(896 \pm 2 \mathrm{cp})$ and KLR starch $(631 \pm 2 \mathrm{cp})$. The higher the setback, the more syneresis is likely to take place and this also indicates a higher retrogradation tendency. High setback is also an indication of the amount of swelling power of the starch and is usually related to the amylose content of the starch. The amylose component of the starch retrogrades more readily than amylopectin due to its essentially linear structure. The straight chain structure of amylose allows it to readily form hydrogen bonds between molecules, resulting in rigid gels. The pasting temperature (P Temp) was highest in PLR starch at $\left(72.7 \pm 0.04^{\circ} \mathrm{C}\right)$ followed by HLR starch at $\left(69.3 \pm 0.02^{\circ} \mathrm{C}\right)$ and $\mathrm{KLR}$ starch at $\left(60.3 \pm 0.4^{\circ} \mathrm{C}\right)$. Hizukuri et al. [36] reported similar values of pasting temperature for water chestnut at $71^{\circ} \mathrm{C}$.

\section{Thermal properties}

The gelatinization temperatures (onset, To; peak, Tp; and conclusion, $T \mathrm{c}$ ), enthalpy of gelatinization ( $\Delta \mathrm{Hgel})$, for starches from different sources measured by using DSC are presented in (Table 4).
KLR starch showed the highest gelatinization temperatures which suggest that more energy is required to initiate gelatinization. Lowest values for $T o, T p$ (onset temperature, peak temperature) were recorded for HLR starch whereas PLR starch exhibited intermittent values between the other two sources (Figure 4). KLR starch also exhibited highest $T \mathrm{c}$ (conclusion temperature) of $\left(89.66 \pm 0.3^{\circ} \mathrm{C}\right)$, followed by PLR and HRL starch at $\left(86.19 \pm 0.02^{\circ} \mathrm{C}\right)$ and $\left(82.53 \pm 0.03^{\circ} \mathrm{C}\right)$, respectively. Factors such as granule shape, percentage of large and small granules, and the presence of phosphate esters are all reported to affect the gelatinization enthalpy [37]. $\Delta H_{\text {gel }}$ observed for different starches were $(14.23 \pm 0.2 \mathrm{~J} / \mathrm{g}),(12.66 \pm 0.02 \mathrm{~J} / \mathrm{g})$ and $(12.21 \pm 0.02 \mathrm{~J} / \mathrm{g})$ for KLR, PLR and HLR starches, respectively. McPherson and Jane [38] reported that the difference in $\Delta H_{\text {gel }}$ reflects melting of amylopectin crystallites. The variations in $\Delta H_{\text {gel }}^{\text {gel }}$ could represent differences in bonding forces between the double helices that form the amylopectin crystallites which resulted in different alignment of hydrogen bonds within starch molecules.

\section{Morphological properties}

Granules size and particle size distribution markedly influence the functional properties of starch granules. Results obtained in this study are in comparison with earlier morphological studies on lotus root starch [20]. Starches from all the three sources showed oval to elongated shape with small and large size respectively with some dents and ridges, when viewed under two magnifications of $1000 \mathrm{X}$ and 1500X. The size of the granules from all the three sources ranged from $10 \mu \mathrm{m}-50 \mu \mathrm{m}$. Starches from HLR were mostly oval, Figures $5 \mathrm{a}$ and $5 \mathrm{~b}$. Starches from PLR were elongated, Figures $5 \mathrm{c}$ and $5 \mathrm{~d}$. However the KLR starch showed both oval and elongated shapes with smooth surfaces, Figures $5 e$ and $5 f$. The difference in granule morphology may be attributed to

\begin{tabular}{|c|c|c|c|c|c|}
\hline Source & $\mathbf{T}_{o}\left({ }^{\circ} \mathbf{C}\right)$ & $\mathbf{T}_{\mathrm{p}}\left({ }^{\circ} \mathbf{C}\right)$ & $\mathbf{T}_{\mathrm{c}}\left({ }^{\circ} \mathbf{C}\right)$ & $\mathbf{\Delta T}_{\mathbf{c}} \mathbf{T}_{\mathrm{c}}-\mathbf{T}_{\mathrm{o}}$ & $\mathbf{H}(\mathbf{J} / \mathbf{g})$ \\
\hline KLR & $61.56 \pm 0.3$ & $75.31 \pm 0.02$ & $89.66 \pm 0.3$ & $28.33 \pm 2.5$ & $14.23 \pm 0.2$ \\
\hline PLR & $59.94 \pm 0.02$ & $73.24 \pm 0.03$ & $86.19 \pm 0.02$ & $26.23 \pm 0.01$ & $12.66 \pm 0.02$ \\
\hline HLR & $58.75 \pm 0.03$ & $71.74 \pm 0.03$ & $82.53 \pm 0.03$ & $23.79 \pm 0.02$ & $12.21 \pm 0.02$ \\
\hline
\end{tabular}

Values are the means \pm standard deviations of the means at least three determinations $n=3$ where, $T_{0}$-onset temperature, $T_{p}$ - peak temperature, $T_{c}$ conclusion temperature, $\mathrm{H}$-enthalpy

Table 4: Thermal properties of KLR, PLR and HLR starches.

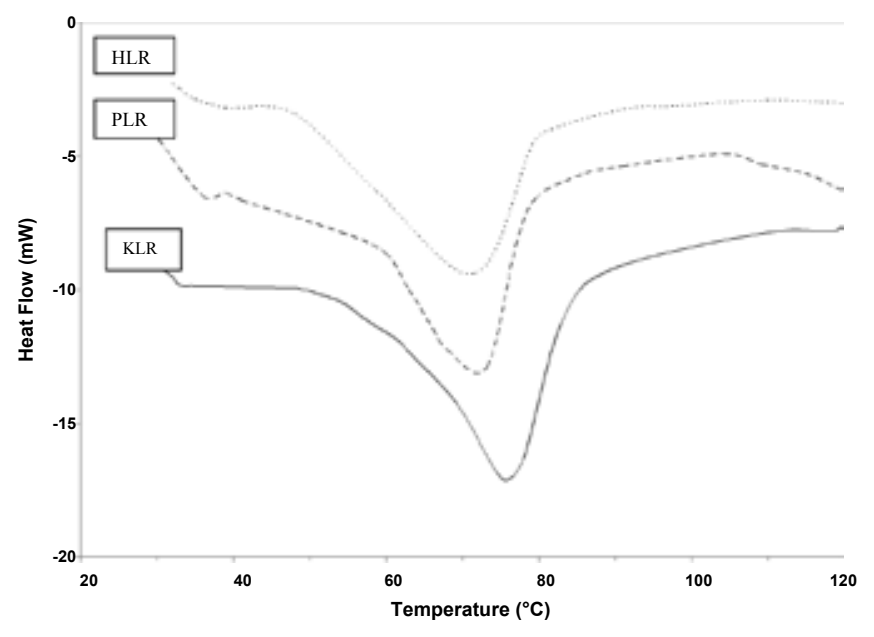

Figure 4: DSC characteristics of KLR, PLR, HLR starches. 
Citation: Syed A, Singh S (2013) Physicochemical, Thermal, Rheological and Morphological Characteristics of Starch from Three Indian Lotus Root (Nelumbo Nucifera Gaertn) Cultivars. J Food Process Technol S1: 003. doi:10.4172/2157-7110.S1-003

Page 6 of 7
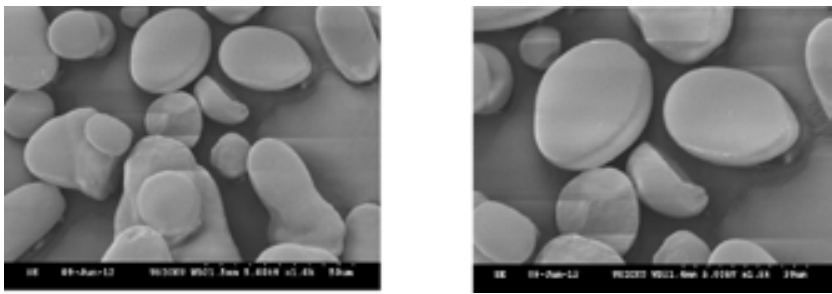

(HLR) 1000x

(a)

$\mathbf{x}(\mathbf{b})$
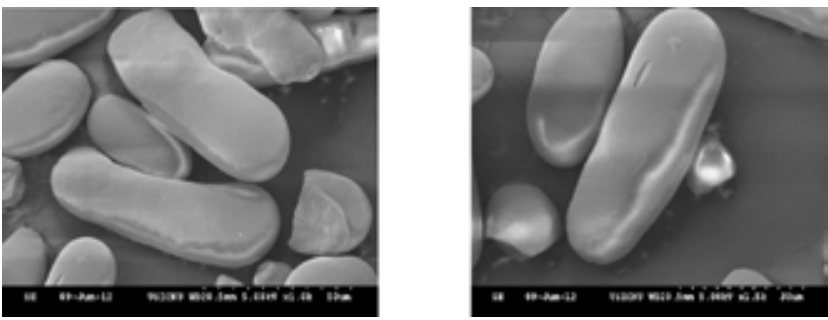

(PLR)

$\mathbf{x}(\mathbf{c})$

1000

$\mathbf{x}(d)$

1500

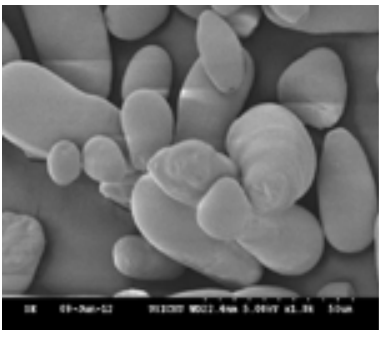

(KLR)

$1000 x(e)$

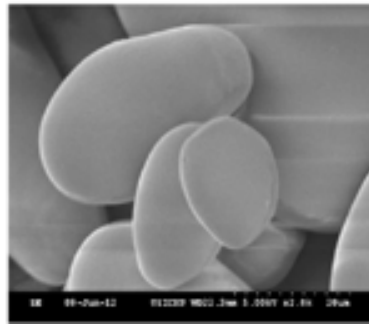

1500x (f)

Figure 5: Scanning electron micrograph of lotus root starches at different magnifications.

the biological origin, biochemistry of the amyloplast and physiology of the plant [39].

\section{Conclusions}

The starches separated from three different lotus root cultivars were investigated for physicochemical, thermal, morphological and pasting properties. The amylose content and water binding capacity of PLR variety is higher than HLR and KLR. The pasting properties of three sources differ significantly. The peak viscosity and pasting temperature of PLR is higher than HRL and KLR. The value of peak temperature of PLR is significantly different from HLR and KLR. The turbidity value of gelatinized starch pastes in PLR is lower than HLR and KLR. The high amylose content and water binding capacity of PLR makes it useful as a thickener in liquid and semi solid foods. Thermal and pasting properties show that easy gelatinization of starch can make them suitable in the manufacture of hydrolysis products derived from starches. The range of characteristics observed makes the PLR variety of lotus root starch amenable to different application based on their properties and can also make this native starch from non-conventional sources an excellent alternative to normal conventional starches from tubers.

\section{References}

1. Wang LZ, White PJ (1994) Structure and Properties of Amylose, Amylopectin and Intermediate Materials of Oat Starches. Cereal Chem 71: 263-268.

2. Moorthy SN (2002) Physicochemical and Functional Properties of Tropical Tuber Starches: A review. Starch/Stärke 54: 559-592.

3. Zhong G, Chen Z, We Y (2007) Physicochemical properties of lotus (Nelumbo nucifera Gaertn.) and kudzu (Pueraria hirsute Matsum.) starches. Int J Food Sci Tech 42: 1449-1455.

4. Hong HJ, Gross KC (1998) Surface sterilization of whole tomato fruit with sodium hypochlorite influence subsequent postharvest behavior of fresh-cut slice. Postharvest Biol Tec 13: 51-58.

5. Singh N, Inouchi N, Nishinari K (2006) Structural, thermal and viscoelastic characteristics of starches separated from normal, sugary and waxy maize. Food Hydrocolloid 20: 923-935

6. American Association of Cereal Chemists (1995) Approved methods of the American Association of Cereal Chemists. 11th ed. Method 46-13.01. St. Paul, Minn., USA.

7. Association of Analytical Chemists (1981) Official methods of analysis of AOAC. 14th ed. Washington D.C., USA

8. Rahman SMM, Joshee L, Rakshit SK, Wheatley C, Stevens WF, et al. (1998) Comparative study of starch content measurement and extractability in different sweetpotato varieties. In: Proceedings of the International Agricultural Engineering Conference, Bangkok, Thailand P: 402-411.

9. Ranganna S (1999) Handbook of analysis and quality control for fruit and vegetable products. 2 nd ed. Tata McGraw Hill, New Delhi.

10. Williams PC, Kuzina FD, Hlynka I (1970) A Rapid Calorimetric Procedure for Estimating the Amylose Content of Starches and Flours. Cereal Chem 47: 411 421.

11. Elizabeth MN, Janice D, Chris FM, John RNT (2003) Granule Integrity and Starch Solubility During Slow, Extended Pasting of Maize Starch- The Second Viscosity Peak. Starch/Starke 55: 72-79.

12. Jyothi AN, Moorthy SN, Vimala B (2003) Physicochemical and Functional Properties of Starch from Two Species of Curcuma. Int J Food Prop 6: 135-145.

13. Yamazaki W T (1953) An alkaline water retention capacity test for the evaluation of cookie baking potentialities of soft winter wheat flours. Cereal Chemistry 30 : 242-246.

14. Medcalf DG, Gilles KA (1965) Wheat Starches. I. Comparison of Physicochemical Properties. Cereal Chem 42: 558-568.

15. Leach HW, McCowen LD, Schoch TJ (1959) Structure of the starch granule. Swelling and solubility patterns of various starches. Cereal Chemistry 36: 534 544.

16. Singh S, Raina CS, Bawa AS, Saxena DC (2006) Effect of Pretreatments on Drying and Rehydration Kinetics and Color of Sweet Potato Slices. Dry Techno 24: $1487-1494$

17. Perera C, Hoover R (1999) Influence of hydroxypropylation on retrogradation properties of native, defatted and heat-moisture treated potato starches. Food Chem 64: 361-375

18. Walter WM, Purcell AE (1980) Effect of substrate levels and polyphenol oxidase activity on darkening in sweetpotato cultivars. J Agric Food Chem 28: 941-944.

19. Anil G, Harold C (2007) Functional Properties of Hydroxypropylated, CrossLinked, and Hydroxypropylated Cross-Linked Tuber and Root Starches. Cereal Chem 84: 30-37.

20. Man J, Jinwen C, Canhui C, Bin X, Huyin H, et al. (2012) Comparison of physicochemical properties of starches from seed and rhizome of lotus. Carbohyd Polym 88: 676-683.

21. Hoover R, Sosulski F (1986) Effect of Cross-Linking on Functional Properties of Legume Starches. Starch/Stärke 5: 149-155.

22. Wotton M, Bamunuarachchi A (1978) Water Binding Capacity of Commercial Produced Native and Modified Starches. Starch/Stärke 30: 306-309.

23. Rickard JE (1991) Review of the physicochemical properties of cassava starch Tropical Science 31: 189-207. 
Citation: Syed A, Singh S (2013) Physicochemical, Thermal, Rheological and Morphological Characteristics of Starch from Three Indian Lotus Root (Nelumbo Nucifera Gaertn) Cultivars. J Food Process Technol S1: 003. doi:10.4172/2157-7110.S1-003

24. Tester RF, Morrison WR (1990) Swelling and Gelatinization of Cereal Starches. I. Effects of Amylopectin, Amylose and Lipids. Cereal Chem 67: 551-557.

25. Svegmark K, Hermansson AM (1993) Microstructure and rheological properties of composites of potato starch granules and amylose: a comparison of observed and predicted structure. Food Struct 12: 181-193.

26. Lee YE, Osman EM (1991) Correlation of morphological changes of rice starch granules with rheological properties during heating in excess water. J Korean Agric Chem Soc 34: 379-385

27. Tester RF, Karkalas J (1996) Swelling and Gelatinization of Oat Starches. Cereal Chem 73: 271-277.

28. Galvez FCF, Resurreccion AVA (1992) Reliability of the focus group technique in determining the quality characteristics of mungbean (Vigna Radiata (L.) Wilczec) noodles. J Sens Stud 7: 315-326.

29. Jacobson MR, Obanni M, BeMiller JN (1997) Retrogradation of Starches from Different Botanical Sources. Cereal Chem 74: 511-518.

30. Ghiasi K, Marston VE, Hoseney RC (1982) Gelatinization of Wheat Starch. II. Starch-Surfactant Interaction. Cereal Chem 59: 86-88.

31. Thomas DS, Atwell WA (1999) Starch Structure. In: Starches. Critical guides for the food industry. (Series Ed.), Eagan Press Handbook series. pp. 25-30.
32. Shibanuma Y, Takeda Y, Hizukuri S (1996) Molecular and pasting properties of some wheat starches. Carbohyd Polym 29: 253-261.

33. Whistler RL, BeMiller JN (1997) Carbohydrate chemistry for food scientists Eagan Press, Minnesota, USA

34. Miles MJ, Morris VJ, Orford PD, Ring SG (1989) The roles of amylose and amylopectin in the gelation and retrogradation of starch. Carbohyd Res 135: 271-281.

35. Karim AA, Norziah MH, Seow CC (2000) Methods for the study of starch retrogradation. Food Chem 71: 9-36.

36. Hizukuri S, Takeda Y, Shitaozono T, Abe J, Ohtakara A, et al. (1988) Structure and Properties of Water Chestnut (Trapa natans L.var.bispinosa Makino) Starch. Starch-Stärke 40: 165-171.

37. Yuan RC, Thompson DB, Boyer CD (1993) Fine structure of amylopectin in relation to gelatinization and retrogradation behavior of maize starches from three wax-containing genotypes in two inbred lines. Cereal Chem 70: 81-89.

38. McPherson AE, Jane J (1999) Comparison of waxy potato with other root and tuber starches. Carbohyd Polym 40: 57-70.

39. Seidemann J (1970) Badenhuizen, N. P.: The Biogenesis of Starch Granules in Higher Plants. Appleton-Century-Crofts, New York 1969. 121 S., 34 Abb., Ganzleinen US \$ 5.00. Starch-Stärke 22: 102-103. 